East African Medical Journal Vol. 86 No. 7 July 2009

USE OF INSECTICIDE TREATED NETS AMONG CAREGIVERS OF CHILDREN UNDER FIVE YEARS IN MAKUENI DISTRICT, KENYA

J. M. Malusha, MPH, Senior Public Health Officer, Ministry of Public Health and Sanitation, P.O. Box 172-01100, Kajiado, Kenya, I. Mwanzo, PhD, Lecturer, A. Yitambe, PhD, Lecturer and J. P. Mbugi, PhD, Lecturer, Kenyatta University, P.O. Box 43844-0100, Nairobi, Kenya

Request for reprints to: Mr. J. M. Malusha, Ministry of Public Health and Sanitation, P.O. Box 172-01100, Kajiado, Kenya

\title{
USE OF INSECTICIDE TREATED NETS AMONG CAREGIVERS OF CHILDREN UNDER FIVE YEARS IN MAKUENI DISTRICT, KENYA
}

\author{
J. M. MALUSHA, I. MWANZO, A. YITAMBE and J. P. MBUGI
}

\begin{abstract}
Background: Insecticide treated nets (ITNs) have been identified as a key strategy in addressing malaria problem among young children and pregnant women. Their utilisation among under fives, however, have been found to be low in some areas. Objective: To identify factors affecting net utilisation (sleeping under insecticide treated net) among caregivers of under fives in Makueni District in Kenya.

Design: A cross-sectional, descriptive study.

Setting: Eight sub-locations in Wote division Makueni district.

Subjects: Four hundred caregivers of children aged five years and below.

Results: The results indicated that $88.5 \%$ of caregivers were aware of ITNs. The proportion of households with children below five years that owned mosquito net were found to be $46.2 \%$, and only $32.0 \%$ had at least a treated net. Slightly more than half of treated nets were used by under fives $(52.2 \%)$ compared to $47.8 \%$ used by children over five years including adults. The main reason cited by majority of caregivers as a hindrance to net utilisation was lack of treated nets in households $(72.3 \%)$. Utilisation of ITNs by under five children was found to be positively associated with knowledge of ITNs ( $p=0.024)$, marital status ( $p=0.018)$ and occupation ( $p=0.043)$.

Conclusion: Utilisation of ITNs by under fives was low despite high level of awareness among caregivers. Factors such as awareness of ITNs, marital status and occupation significantly affected ITNs utilisation. Although the government with support from other stakeholders has recently embarked on large scale distribution of nets in high risky districts, more interventions from various stakeholders are needed to increase availability and accessibility of subsidised permanently treated nets, including interventions to address non-compliance to proper utilisation of nets. There is also need for intensive education emphasising on their proper and consistent use. Scaling up proper use of ITNs along with other initiatives can contribute significantly in reducing malaria.
\end{abstract}

\section{INTRODUCTION}

Malaria, a disease transmitted by anopheles mosquitoes, is a major public health problem in many countries in the world affecting the lives of many people either directly or indirectly. It is estimated that nearly half of the world's population live in countries with high risk of contracting malaria. World wide, 300500 million malaria cases are estimated to occur each year resulting in about one million deaths, with $40 \%$ of the world's population being at risk of contracting the disease, and about nine out of ten of the global cases occurring in Africa (1). Sub-saharan Africa constitutes over $90 \%$ of the world disease burden with over 300 million cases of malaria every year. It is further estimated that the disease kills almost one million children a year in Africa alone, and accounts for $4.5 \%$ of Disability Adjusted Life Years (DALYs) in children aged 0-4 years (2).

InKenya, malariais theleading cause of morbidity and mortality. It is estimated that over $70 \%$ of the population are at the risk of the disease that claims 26,000 children (about 72 per day) annually (3).

The Roll Back Malaria global partnership aims to halve malaria mortality by 2010 through scaling up ITN use, improving case management, controlling malaria in pregnancy and containing epidemics $(4,5)$. 
Insecticide treated nets (ITNs) are an effective and cost-effective means of preventing malaria and substantial reductions in all cause child mortality have been demonstrated in controlled efficacy trials $(6,7)$, and there had been no increase in mortality in older children who have been using ITNs from birth (8). However, coverage and use of ITNs is substantially low, especially in pregnant women and under five children who are more vulnerable to malaria. In Kenya, ITN coverage is quite low.

Surveys done estimates that in 2002 only 22\% of households had at least one net, out of which $6 \%$ were treated, while $15 \%$ of under fives used nets out of which $5 \%$ were treated (9). However survey done by population service international (PSI) in 2006 indicated that coverage had increased to $46 \%$ (PSI national survey, 2006). In other areas, net ownership and use of ITNs among the under fives has also been observed to be low, despite evidence on their effectiveness (10). Similarly, adoption of ITN'S has been slow leading to low utilisation of nets (11). Further even where ITNs are available many under fives do not always sleep under them at night.

This paper reports the findings of a study that explored factors influencing mosquito net utilisation (sleeping under net always at night) among the caregivers of under fives in households in Makueni district.

\section{MATERIALS AND METHODS}

The study was conducted in Makueni district of Eastern Province, Kenya. It was a cross- sectional study to factors influencing treated mosquito net utilisation among the caregivers of under fives in Makueni district. The study included all caregivers of children below five years who were above 18 years of age and living in households within the study area. It excluded caregivers who were below 18 years (save for mothers of under fives) and those who did not have children below five years.

Wote division was randomly chosen among the 16 divisions in the district. Probability proportional to size was used to determine the number of households included in the study from each sublocation. First, the number of households sampled were selected proportionally to the size of the sublocation. Second, villages (clusters) in sub-locations were selected randomly by simple random method. Third, households were then selected randomly by simple random sampling procedure.

Data were collected using interview schedules, which were administered to 400 caregivers of under fives in household. Focus group discussions (FGDs) were conducted to obtain more qualitative information to corroborate data collected using interview schedules. The study started with data collection in 2006 and was completed in early 2007. The data collected was edited, coded and entered into computer using Ms Excel software. The analysis of data was carried out using statistical package for social sciences (SPSS). Descriptive statistics were applied in order to group and summarise data. Chi- square test for independence was used to determine association of categorical variables.

Analysis of variance (ANOVA) was used to compare means and where means were significant turkey test was applied. Correlation coefficient was used to analyse relationship of quantitative variables. For all statistical tests a 2 -sided $\mathrm{p}<0.05$ was considered statistically significant.

\section{RESULTS}

Socio-demographic characteristics of respondents: Four hundred caregivers (respondents) were interviewed. The majority $355(88.7 \%$ ) of respondents werefemales while $45(11.3 \%)$ were males. Their age varied considerably with majority $(65.5 \%)$ aged between 18-30 years. About $126(31.5 \%)$ of respondents had completed primary education while $102(25.5 \%)$ had secondary level of education, while the rest had either some primary, some secondary, post secondary education or no formal education (never been to school).

Themain source of incomeamong thehouseholds was farming $189(47.3 \%)$ followed by business 85 $(21.3 \%)$, salary $75(18.7 \%)$ and casual/ temporary jobs $51(12.7 \%)$. The majority $207(51.7 \%)$ of households had a monthly income of between Kshs 0 to 2500 (US\$ 0 to 34$)$, while a considerable proportion $106(26.5 \%)$ had income ranging between Khs 2500 to 5000 (US\$ 34 to 68$)$.

Awareness of insecticide treated net: The majority 354 $(88.5 \%)$ of respondents were aware of insecticide treated mosquito nets (ITNs).

Household coverage with treated and untreated mosquito nets: In all households interviewed $128(32.0 \%)$ had at least a treated net, while $57(14.2 \%)$ had untreated net. Hence households with at least a net (either treated or untreated) were 185, giving coverage of $46.2 \%$. The majority of households $215(53.8 \%)$ had no net at all. Out of the 185 households with any net (either treated or untreated), only $128 / 185(69.2 \%)$ had treated net while $57 / 185(30.8 \%)$ had untreated net.

Utilisation of treated and untreated mosquito net in household: Analysis on use of any net by household members showed that $190(49.6 \%)$ were availed for use by children under five years whilst 193 (50.4\%) were availed for use by those over five years, indicating that a higher proportion of nets were used by older children and adults. The results further indicated that not all treated nets in household were made available for use by under fives. Of the 249 treated nets available in the household, only $130(52.2 \%)$ were for the under 
fives while 119(47.8\%) were used by children over five years and adults. Table 1 shows utilisation of any net and treated net in household.

Table 1

Utilisation of any net and treated net in household

\begin{tabular}{lcc}
\hline & Any net $(\%)$ & Treated net $(\%)$ \\
\hline Under fives & 49.6 & 52.2 \\
Over fives and adults & 50.4 & 47.8 \\
\hline
\end{tabular}

Treated net utilisation by children under five years: About $58(31.5 \%)$ households had no child who slept under treated net, $90(48.9 \%)$ had one child who slept under treated net, $31(16.9 \%)$ had two children who slept under treated net, four $(2.2 \%)$ had three children who slept under treated net, and one $(0.5 \%)$ had four children who slept under treated net, the previous night to the interview. Regarding those who slept under untreated net, 31(36.0\%) of households had no child who slept under untreated net, $37(43.0 \%)$ had one child who slept under untreated net, $16(18.7 \%)$ had two children who slept under untreated net, and two $(2.3 \%)$ had three children who slept under untreated net. Table 2 shows the number of children below five years in the household who slept under treated net the previous night to the interview.

\section{Table 2}

Number of children below five years in household who slept under net the previous night to the interview

\begin{tabular}{lcccc}
\hline $\begin{array}{l}\text { Number of } \\
\text { under fives } \\
\text { slept under }\end{array}$ & \multicolumn{2}{c}{$\begin{array}{c}\text { Slept under } \\
\text { treated net }\end{array}$} & \multicolumn{3}{c}{$\begin{array}{c}\text { Slept under } \\
\text { Frequency }\end{array}$} & $(\%)$ & \multicolumn{2}{c}{ Frequency } & $(\%)$ \\
net & & & & 36.0 \\
\hline 0 & 58 & 31.5 & 31 & 33.0 \\
1 & 90 & 48.9 & 37 & 18.7 \\
2 & 31 & 16.9 & 16 & 2.3 \\
3 & 4 & 2.2 & 2 & \\
4 & 1 & 0.5 & & \\
\hline Total & 184 & 100 & 86 & 100 \\
\hline
\end{tabular}

In some households with more than one child below five years not all children slept under a treated net. In this study, only $30.25 \%(121 / 400)$ of households with treated nets had all their children below five years sleeping under ITN the night preceding the interview.

Sharing of nets among caregivers and children was practiced in some households. This study found that $35.9 \%(65 / 185)$ caregivers were sharing nets with their child/children.

Reasons for non-use of treated nets by children under five years: The majority $(72.3 \%)$ cited lack of mosquito nets, followed by $8.2 \%$ who reported that they could not afford insecticide. Others reasons though cited by fewer respondents were: no mosquitoes (3.2\%), treatment of net not important $(5.0 \%)$, do not know how to treat net $(4.3 \%)$, mosquitonet cause suffocation $(2.5 \%)$, insecticides are not available $(2.5 \%)$, and insecticides are harmful (1.1\%) (Table 3).

Table 3

Reasons for non-use of treated nets by children under five years $(n=272)$

\begin{tabular}{lcc}
\hline Reason & Frequency & $(\%)$ \\
\hline Lack of mosquito nets & 204 & 72.3 \\
Could not afford insecticide & 23 & 8.2 \\
No mosquitoes & 9 & 3.2 \\
Treatment of net not important & 14 & 5.0 \\
Do not know how to treat net & 12 & 4.3 \\
Mosquito net cause suffocation & 7 & 2.5 \\
Insecticides are harmful & 3 & 1.1 \\
\hline
\end{tabular}

Problems perceived to be associated with treated net use: About $19.0 \%$ of respondents reported that insecticides might be harmful to net users, $5.5 \%$ reported that treated nets cause sleep disturbance, $5.0 \%$ said they cause dizziness. A lower but significant proportion $4.2 \%$ said children might die due to heavy sweating when sleeping under treated net. Only $11.8 \%$ did not know any of the problems (Table 4).

Table 4

Problems perceived to be associated with treated net use $(n=182)$

\begin{tabular}{lcc}
\hline Reason & Frequency & $(\%)$ \\
\hline $\begin{array}{l}\text { Insecticides might be } \\
\text { harmful to net users }\end{array}$ & 76 & 19.0 \\
$\begin{array}{l}\text { Treated nets cause } \\
\text { Sleep disturbance }\end{array}$ & 22 & 5.5 \\
$\begin{array}{l}\text { Cause dizziness } \\
\text { children might die due }\end{array}$ & 20 & 5.0 \\
to heavy sweating & & \\
$\begin{array}{l}\text { when sleeping under a } \\
\text { treated net }\end{array}$ & & \\
$\begin{array}{l}\text { Did not know any of } \\
\text { the problems }\end{array}$ & 17 & 4.2 \\
\hline
\end{tabular}

Cross-tabulation results: Results of cross-tabulation of socio-demographic, cultural and economic variables with net utilisation showed that utilisation of ITNs by under five children was positively associated with knowledge of ITNs $\left(X^{2}=11.255\right.$, (Table 5) $\mathrm{df}=4$, $\mathrm{p}=0.024)$, marital status $\left(\mathrm{X}^{2}=29.915, \mathrm{df}=16, \mathrm{p}=0.018\right.$ (Table 6) occupation $\left(\mathrm{X}^{2}=32.008, \mathrm{df}=16, \mathrm{p}=0.043\right.$ (Table 7). 
Table 5

Knowledge of ITN vs children under five years who slept under ITN previous night to the interview

\begin{tabular}{|c|c|c|c|}
\hline \multirow{2}{*}{$\begin{array}{l}\text { Children }<5 \text { years slept } \\
\text { under treated net } \\
\text { previous night }\end{array}$} & \multicolumn{2}{|c|}{$\begin{array}{c}\text { Knowledge of } \\
\text { ITN }\end{array}$} & \multirow[t]{2}{*}{ Total } \\
\hline & Yes & No & \\
\hline 0 & 48 & 10 & 58 \\
\hline 1 & 87 & 3 & 90 \\
\hline 2 & 30 & 1 & 31 \\
\hline 3 & 4 & & 4 \\
\hline 4 & 1 & & 1 \\
\hline Total & 170 & 14 & 184 \\
\hline
\end{tabular}

Table 6

Marital status vs children under five years who slept under treated net previous night preceding the interview

\begin{tabular}{|c|c|c|c|c|c|c|}
\hline \multirow[b]{2}{*}{ Marital status } & \multicolumn{5}{|c|}{$\begin{array}{l}\text { Children under five } \\
\text { years slept under } \\
\text { treated net } \\
\text { previous night }\end{array}$} & \multirow[b]{2}{*}{ Tota } \\
\hline & 0 & 1 & 2 & 3 & 4 & \\
\hline Married & 46 & 59 & 24 & 2 & 0 & 131 \\
\hline Single/never married & 9 & 24 & 5 & 0 & 1 & 39 \\
\hline Divorced & 0 & 2 & 1 & 1 & 0 & 4 \\
\hline Separated & 2 & 3 & 1 & 0 & 0 & 6 \\
\hline Widowed & 1 & 2 & 0 & 1 & 0 & 4 \\
\hline Total & 58 & 90 & 31 & 4 & 1 & 184 \\
\hline
\end{tabular}

(Chi-square $=29.915, \mathrm{df}=16, \mathrm{p}=0.018$ )

Table 7

Caregiver occupation vs children under five years who slept under treated net the previous night to the interview

\begin{tabular}{lccccccc}
\hline & \multicolumn{7}{c}{ Children under 5 years who } \\
slept under treated net \\
Previous night \\
Occupation & 0 & 1 & 2 & 3 & 4 & Total \\
\hline Farming & 23 & 9 & 9 & 1 & 1 & 43 \\
Business & 15 & 38 & 7 & 0 & 0 & 60 \\
Skilled employee & 7 & 20 & 9 & 2 & 0 & 38 \\
Unskilled employee & 5 & 7 & 1 & 0 & 0 & 13 \\
None/house wife & 8 & 16 & 5 & 1 & 0 & 30 \\
\hline Total & 58 & 90 & 31 & 4 & 1 & 184 \\
\hline (Chi-square $=32.008$, & $\mathrm{df}=16, \mathrm{p}=0.043)$ & & &
\end{tabular}

(Chi-square $=32.008, \mathrm{df}=16, \mathrm{p}=0.043$ )

\section{DISCUSSION}

Insecticide treated net utilisation was generally low despite high level of community awareness $(88.5 \%)$ in the area, implying that majority of people were not protected by use of this intervention. This was consistent with other studies $(9,12,13)$. As young children especially the under fives are more vulnerable to malaria, much focus has been on increasing ITN use. In this study only half of the nets available in households were accessible to under fives for use. Further even when ITNs are accessible only two-thirds were found to have slept under them the night preceding the interview. Yet for ITNs to be able to offer any meaningful protection against malaria they need to be used consistently. This finding is consistent with other studies (14-17).

The main concern on ITN use in household has been how well the child is protected against malaria, and especially in relation to other household members, since not all nets available in household are used by under fives. This study revealed that whereas $49.6 \%$ of any nets (treated and untreated) in household were reportedly used by under five year old children, $52.2 \%$ of treated nets were used by same age group. The relatively higher usage of treated nets by under fives could have been attributed to the intensive promotional campaigns that had been focusing on ITNs use by under fives.

Regarding children who slept under treated net on the night preceding the interview, not all children below five years slept under them despite being available in the household. Only $68.5 \%$ slept under treated net the previous night giving ITN noncompliance rate of $31.5 \%$ which is slightly lower than the average $35 \%$ achieved under trial conditions in Gambia (14). These finding are close to those of a study done by Korenromp et al (15) which monitored ITN coverage in Africa, and found out that out of the households that owned ITN, only $55 \%$ of children slept under it.

In some situations, where households had more than one child and had inadequate ITNs, the age of a child determined who slept under the net. It emerged during FGDs that if there was more than one child in a household preference was given to the youngest child: "youngest child is given preference because of being tender and weak", remarked one woman from Kivandini village.

In some households that owned nets, caregivers were found to be sharing nets with children. In such a situation, children used mosquito nets because they happened to share a bed with the caregiver, thus giving these children a comparative advantage over the others. In fact Mugisha et al (10) in their 
study noted that a child who shared a bed with the mother was 21 times more likely to use a mosquito net than his / her counterpart. Since a younger child was likely to share a bed with parents, it implies that a younger child was more likely to sleep under net if it was available.

There were also other hindrances that affected use of ITNs by under fives. For instance, although studies have shown that treated nets are safe and have no adverse effects $(19,20)$, their use have been perceived to be associated with some problems. In this study, caregivers perceived use of ITNs to be associated with dizziness, sleep disturbance or discomfort due to heavy sweating that resulted when one slept under ITN. This perception might reduce adherence or compliance rate of ITN use by under five year old children. Conversely, a study conducted in Uganda (10), revealed that children in cold climates used nets to keep them warm. Therefore availing nets made of light materials like nylon or polyester could overcome discomfort experienced in use of nets in hot and dry climates.

The results have also indicated that the use of ITNs was affected by several factors such as knowledge onITNs, marital status and the occupation of caregiver. Knowledge on ITN was positively associated with the use of ITNs by under five year old children $(p=0.024)$. The implication of this finding is that, children whose caregivers were aware of ITN were more likely to sleep' under net than children whose caregivers were not aware of them.

Likewise, there was significant positive association between marital status and use of ITN by under five year old children $(p=0.018)$. The implication of this finding is that those caregivers who were married were more likely to own ITNs, and their children were more likely to sleep under nets compared to those who were not married or living together with their partners. These findings support the observation from another author (10) which found that children of married mothers or those mothers who were living with their partners were more likely to use mosquito nets compared to children whose mothers were never married. Similarly, there was a significant positive association between occupation and use of ITNs by children $(\mathrm{p}=0.043)$. This finding indicated that occupation of caregiver had a positive effect on ITN use by under fives, and was contrary to the view that households whose mothers had vocational training, their children were less likely to use mosquito nets (10). This implies that occupation of a caregiver influences proper utilisation of ITNs.

As efforts are made to increase ITN ownership by government and various stakeholders, similar efforts should be made to increase their proper utilisation and compliance in their use through intensive and consistent public education.

\section{CONCLUSION}

In conclussion, the usage of insecticide treated nets by under fives was low despite the high level of awareness in the community about them. Besides, even some households with nets were not using them consistently. Factors such as knowledge of ITN, level of education, marital status and occupation of caregiver affected ITN utilisation by under fives in households. Thus, interventions to increase net ownership and use among under fives should take into consideration these factors.

Finally, although the government with support from other stakeholders has recently embarked on large scale distribution of nets in high risky districts, more interventions from various stakeholders are needed to increase availability and accessibility of subsidised permanently treated nets, including interventions to address non-compliance to proper utilisation of nets. Further efforts to increase ITN coverage should be matched with efforts to increase their proper utilisation. There is need also therefore, in addition to increasing ITN ownership, to educate caregivers on the importance of using ITNs properly and consistently. Proper utilisation of ITN, along with other initiatives such as indoor residual spraying might greatly contribute in reducing malaria.

\section{ACKNOWLEDGEMENTS}

To the Department of Public Health, School of Health Sciences, Kenyatta University for the permission to carry out this study and to publish the findings.

\section{REFERENCES}

1. World Health Organization (WHO). The African Summit on Roll Back Malaria. 2000: WHO/CDS/ $\mathrm{RBM} / 2000.17$.

2. WHO. The use of Antimalaria drugs: a report of $\mathrm{WHO}$ informal consultation. 2000. Roll Back Malaria pp. 5-6.

3. MOH-ROK. National Malaria Strategy: 2001-2010. Ministry of Health (MOH), Republic of Kenya (ROK) April 2001.

4. Nabarro, D.N., and Tayler, E.M. The "Roll Back Malaria" campaign. Science. 1998; 280: 2067- 2068.

5. WHO. The Abuja declaration on Roll Back Malaria in Africa by the African Heads of state and Government, April 2000, Abuja Nigeria. Statement prepared by RBM, WHO, Geneva April 2000.

6. Nevil, C.G. and Some, E.S. Insecticide-treated bedmates reduce mortality and severe morbidity from malaria among children on the Kenyan coast. Clinical research Centre, Kilifi unit, KEMRI, Kenya (Pub Med) 1993.

7. Lengeler, C. Insecticide treated bed nets and curtains for malaria control (Cochrane review). The cochrane library, Oxford: 2000. Update software. 
8. Lindblade, K.A,Eisele, T.P.,Gimning, 1.E., et al. Sustainability of reductions in malaria transmission and infant mortality in Western Kenya with use of insecticide-treated bed nets. J. Amer. Med. Assoc. 2004; 291: 2571-2580.

9. Central Bureau of Statistics.Kenya Demographic Health Survey 2003. Central Bureau of Statistics (CBS). Republic of Kenya (ROK) 2004.

10. Mugisha, F. and Arinatwe, J. Sleeping arrangements and mosquito net use among under fives: results from Uganda Demographic and Health Survey (Pub Med.) 2003.

11. Goodman, C., Coleman, P. and Mills, A. Economic analysis of malaria control in sub-saharan Africa, February 2003.

12. Osero, J.O., Orago, S.S., and Otieno, M.F. Maternal use of Insecticide treated nets in the prevention of malaria among children under five years in Nyamira distict, Kenya. East Afr. Med. J. 2005; 82: 495-500.

13. Guyatt, H. L., Ochola, S. A. and Snow, R. W. Too poor to pay: charging for insecticide treated bedmates in highland Kenya. Trop. Med. Intern. Hlth. 2002; 7: 846850.

14. Hanson K., Goodman c., Lines J., Meek S., Bradely D. The economics of malaria control interventions. Global Forum for Health Research. Geneva, Switzerland. 2004.

15. Korenomp, L. E., Miller, I, Cibulski, E. R., et al. Monitoring mosquito net coverage for malaria control in Africa: Possession vs use by children under five years. Trop. Med. Int. Hlth. 2003; 8: 693-703.

16. Heggenhougen, H. K., Hackethal, V., and Spielman, A. The behavioural and social aspects of malaria and its control UNDP / WORLD BANK/ WHO. Special Programme for Res. Train. Trop. Dis. (TDR). 2003;

17. Kikumbih, N.,Hanson, K, Mills, Aetal. Theeconomics of social marketing: the case of mosquito nets in Tanzania. Social Sci. Med. 2005; 60: 369-381.

18. Winch, P. I., Makemba, A. M., Makeme, V.R. and Mfaume S. Social and cultural factors affecting rates of regular treatment of mosquito nets with insecticides in Bagamoyo district, Tanzania. Trop. Med. Intern. Hlth. 1997; 2: 760- 770.

19. WHO.Guidelines on the use of insecticide treated mosquito nets for prevention and control of malaria in Africa. WHO Division of Control of Tropical disease. Geneva. 1997 vol. 4. 